\title{
Students' Attitudes towards Vocabulary Learning and Their Learning Strategies
}

\author{
Fadiel Mohammed Musa \\ Ph.D., Assistant Professor \\ Department of English Language \\ Nahda College \\ Omdurman, Khartoum, Sudan \\ fadielmoosa@yahoo.com
}

\begin{abstract}
This study aims at investigating (a) students' attitudes towards vocabulary learning and (b) vocabulary studying strategies they use. The study was directed to First Year Students who were specialized in English Language(2019-2020), in Nahda College; Sudan. Twenty six male and female students were involved in the study. A questionnaire consisted of vocabulary learning awareness and vocabulary learning strategies (VLS) was distributed to the participants. A modified Likert Scale (agree, neutral, disagree) was used to collect data. The tables containing figures and percentages were utilized to describe results. The results findings are: Students had noticeable attitudes towards vocabulary importance. The learners used all five (VLS) categories; cognitive, determination, memory, metacognitive, and social strategies frequently, but unequally. The most strategy used is the "Cognitive Strategy" and the least one is the "Social Strategy".
\end{abstract}

Keywords: Vocabulary Awareness, Vocabulary Learning Strategies (VLS) 


\section{0. Introduction}

Vocabulary knowledge is the heart of language learning if learners want to develop in their L2 study. The importance of vocabulary comes from the necessity of understanding of the message concealed behind words. Unless someone knows the words, no meaning could be communicated. Wilkins (1972, p.11) quoted in Larsson $(2014$, p. 1) and Yeh $(2004$, p. 2), states that 'Without grammar very little can be conveyed, without vocabulary nothing can be conveyed.' It is true that EFL learners cannot play active role in listening, speaking, reading or writing skills, inside or outside lecture halls, without noticeable command of the language vocabulary.

So the more demanding and challenging case is the insufficient of vocabulary knowledge among the students who are majored in English language and the mismatch between their level and what is expected from them at this stage.

It is observable that students are always feeling uncomfortable when they have limited vocabulary because they do not recognize main ideas of texts or lectures.

One could say that vocabulary is the building block of the language for constructing sentences, paragraphs, and texts. With poor vocabulary and word knowledge messages and communication could poorly be understood or comprehended. Therefore; students need combat this problem through continuous study.

\section{1. Statement of the Problem}

The aim of this study is to investigate the use of vocabulary learning strategies by EFL undergraduate students in Sudan universities. According to the researcher's experience, first year undergraduate students encounter vocabulary knowledge problems. Students suffer a lot in both: receptive and productive L2 skills due to insufficient and limited vocabulary 
knowledge. Moreover, the students exert little or no effort to build their word size; therefore, the students lack far behind understanding texts and lectures.

\section{2. Questions of the Study}

This case stated in (1.1) above led the researcher to posit these questions:

(a) to what extend are the students aware of vocabulary importance?(b) are the students aware of vocabulary learning strategies (VLSs)?

\section{3. The Aim of the Study}

The objectives of this paper are to raise students' awareness how they can learn vocabulary, to raise their consciousness towards using their strength to increase their learning efficiency.Therefore, the following hypotheses are formed to address the research questions to find out answers to the questions of the study above (1. 1.).The first year undergraduate students are (a) aware of vocabulary importance, but(b) theylack"vocabulary learning strategies" (VLSs)knowledge.

\section{0. Literature Review}

During lectures of English language conducted to English majored first year undergraduate students $2019 / 2020$, the researcher noticed that students were disadvantaged by insufficient vocabulary breadth and knowledge and word-gap.The researcher started reviewing strategies that researchers have revealed trying to close or bridge this gap.

\section{1. Developing Vocabulary Knowledge}

Students mainly develop their vocabulary size through two main traditional activities. Firstly, learners develop vocabulary knowledge when they interact or discuss fields of knowledge with others. For example, if they hear their lecturer says 'theme' while they listen to a lecture about novel. Immediately they ask for explanation of the new word 'theme'. Secondly, students increase the number of vocabulary through lecturer's explicit explanation 
of new or difficult words. Lecturers usually check understanding of new word meaning in texts.

\section{2. Students' Awareness}

Oxford Advanced Learners' Dictionary defines 'awareness' as "knowing something; knowing that something exists and is important". Gross (2019), claims that knowledge of vocabulary at age of thirteen is a predictor of success in GCSE (General Certificate Secondary School Examinations) English literature and Math than those who are disadvantaged.

\section{3. Vocabulary Learning Strategies (VLSs)}

Researchers have explored many vocabulary learning strategies to help students to study effectively. Ali (2016, pp. 4 - 5)quoted the most renowned category of Schmitt (1997) taxonomy proposed as follows:

1- Determination: Learner depends on dictionary or getting meaning from the context.

2- Memory: such as word group, images and pictures.

3- Cognitive: memorizing method, e. g., note taking and repetition of a word its meaning.

4- Meta cognitive: listening to language speakers or listening CDs and watching videos.

5-Social strategies: when learners use social strategies, they mainly depend on speaking to their teachers or colleagues to clarify and get a word meaning.

\section{4. Word Tiers}

Some linguists divide the words into three categories, called 'Tiers Word'; tier word one, two and three.

Tier 1 Words, these are the words that learner use in every day communication. In other words these are the words in daily conversations. Tier 2 Words; they include the words in students' textbooks. Words, such as, rhythm, audience, simile etc... are good example of Tier 
2 Words. They are important words since learners will not be able to understand texts without explaining them.

Finally Tier 3 Words; these are words used in academic fields, e.g., hypothesis, bibliography, verse, etc...

\section{5. Related Studies}

- $\operatorname{Abbas}(2016$, p. 12) conducted a study to explore VLSs used by Sudanese university learners of English language. He found out that Vocabulary Learning Strategies (VLSs) are "... among the most influential factors." The results show that students rarely use English dictionary and memory strategy. The researcher recommends that vocabulary learning strategies should be taught explicitly.

- Adam et al (2017, p. 2), in their study they found out that first-year undergraduate students had done well in vocabulary knowledge after being exposed to vocabulary learning strategies. The students applied VLSs effectively in their academic performance after the post test.

Alfaki (2014, p. 12) conducted a study to investigate the vocabulary load in the syllabi series 'Sudan Practical Integrated National English, Book 5' (SPINE 5). He concludes that'SPINE 5' contains a large number of low frequency words'. The researcher recommendations are: teachers should recycle necessary vocabulary to help students gain useful words.

Holi, I. (2020, p. 361) investigated Omani students' views and perception of understanding lectures in English language. The researcher interviewed twelve students who study engineering. The study aimed to answer how engineering students solve problems 
encountered them while they learn their major in English. The results revealed that students get meaning by discussions through mother tongue, using bilingual dictionary, online translation, and social interaction, such as peers to overcome difficulties and back up their ability to understand texts.

- Mohammed and Ali (2015, p. 1) investigated the influence of vocabulary knowledge size on third-year undergraduate students specialized in English language reading skill in Niyala University; Sudan. They used tests as tools of the study. They found that "Students with high proficiency level of vocabulary breadth were more successful in reading comprehension than those with less proficiency level of vocabulary breadth." The finding indicates that vocabulary breadth has positive impact on reading comprehension.

- Waldvogel (2013, pp. 209 - 219) in his study investigated the relationship between type and size of vocabulary exploited by adult Spanish learners learning beginning, intermediate, and advanced courses. The result indicates that less experienced learners could not manage vocabulary effectively.

To sum up, this difference between this research and the above studies is that all the above studies investigate how students organize and adjust their strategies VLSs to cope with comprehending the language, but this study in addition, investigates learners' awareness of learning L2 vocabulary. That is to say; are the participants in this study aware of the importance of vocabulary in L2 learning?

\section{Methodology}

This study took place in one of Sudan Colleges. The study follows descriptive method with quantitative approach to explore and measure (a) students' awareness of acquiring new vocabulary and (b)vocabulary learning strategies (VLSs) they practice. 
Twenty six students registered in first year English programme participated in the study. They were aged 17 and 18 and they were mixed; males and females EFL learners. All participants were four-year degree students.

The instrument used in the research is the questionnaire. The questionnaire goes under two subtitles: (a) vocabulary learning awareness and (b) vocabulary learning strategies.

Group (b)questions were based on Schmitt's taxonomy (1997) mentioned in 2. 3 above. Schmitt's taxonomy categorized vocabulary learning strategies into: determination, social, memory, cognitive, and metacognitive. The questionnaire was sent to students via e-mail. All students gave their consent to involve in the questionnaire.

4. Results and Discussions

\section{1. Results}

(A) Vocabulary learning awareness

In Table 1(below) the current study reveals that the participants are aware of the importance of vocabulary. The majority of them, $92.2 \%$, agreed with statement three: "Vocabulary knowledge is important to study English language". Yet they do not take sufficient actions and steps towards building vocabulary knowledge since only little above one third of the respondents $(34.5 \%)$ evaluate or devote their time to retrieve vocabulary they have already studied as statements two shows: "I evaluate my knowledge of vocabulary regularly". Responses to the statement "I devote specific time to learn vocabulary" only $36.4 \%$ of the participants allocate specific time to study vocabulary. This assures that students in this group lack practice; which is important to acquire any language skill or other language components.

Looking more closely, the students' responses are approximately equal to the statement "I devote specific time to learn vocabulary". The figures show $36.4 \%$ students agreed, $32.5 \%$ 
are neutral and $31.2 \%$ disagreed with statement 4 . The evidence from statements $(1-4)$ suggest that, the students generally had positive attitude towards vocabulary knowledge since $92.8 \%$ agreed that vocabulary is important to study (see Table 1 below).

Table 1 Vocabulary learning awareness

\begin{tabular}{|c|c|c|c|c|}
\hline No & Statements & agree & neutral & disagree \\
\hline & A- Vocabulary Learning Awareness & & & \\
\hline \multirow[b]{2}{*}{1.} & \multirow[b]{2}{*}{ I usually learn vocabulary to pass exam only. } & 2 & 12 & 4 \\
\hline & & $10.5 \%$ & $67.4 \%$ & $22.1 \%$ \\
\hline \multirow[b]{2}{*}{2.} & \multirow[b]{2}{*}{ I evaluate my knowledge of vocabulary regularly. } & 6 & 9 & 3 \\
\hline & & $34.5 \%$ & $51.7 \%$ & $13.8 \%$ \\
\hline \multirow[b]{2}{*}{3.} & \multirow[b]{2}{*}{$\begin{array}{l}\text { Vocabulary knowledge is important to study English } \\
\text { language. }\end{array}$} & 17 & 1 & 0 \\
\hline & & $92.8 \%$ & $07.2 \%$ & $00 \%$ \\
\hline \multirow[b]{2}{*}{4.} & \multirow[b]{2}{*}{ I devote specific time to learn vocabulary. } & 7 & 6 & 5 \\
\hline & & $36.4 \%$ & $32.5 \%$ & $31.2 \%$ \\
\hline
\end{tabular}

Statements five to eighteen in tables $2,3,4,5$ and 6 were developed for the purpose of investigating students' use of vocabulary learning strategies(based on Schmitt's Taxonomy 1997, see 2.3 above).

To get the meaning of a new word, students use three determination strategies (table 2); i.e., 'Word list', 'Guessing meaning from the context', and 'Mono-lingual dictionary', with scores $60.3 \%, 68 \%$ and $73 \%$ respectively. There is a willingness among the students to use mono lingual dictionary strategy. 
(B) Table 2 Determination (statements 5 to 7 )

\begin{tabular}{|l|l|l|l|l|}
\hline & B- Vocabulary Learning Strategies & agree & neutral & disagree \\
\hline & Determination & & & \\
\hline \multirow{2}{*}{5.} & I often guess word meaning from textual context. & $68 \%$ & $32 \%$ & $00 \%$ \\
\hline \multirow{2nnnnn}{*}{6.} & I always use word lists. & 11 & 3 & 4 \\
\hline & & $60.3 \%$ & $19.2 \%$ & $20.5 \%$ \\
\hline 7. & I use monolingual dictionary to get meaning. & 13 & 5 & 0 \\
& & $73 \%$ & $27 \%$ & $00 \%$ \\
\hline
\end{tabular}

Table 3 Social strategy (statements 8 to 9 )

\begin{tabular}{|l|l|l|l|l|}
\hline \multicolumn{2}{|l|}{ Social strategy } & agree & neutral & disagree \\
\hline & statement & 8 & 4 & 6 \\
\hline \multirow{2}{*}{8.} & I ask teacher for Arabic translation of the meaning. & $45.9 \%$ & $21.4 \%$ & 32.7 \\
\hline \multirow{2}{*}{9.} & I ask friends for meaning. & 7 & 8 & 3 \\
\cline { 3 - 6 } & & $40.6 \%$ & $45.2 \%$ & $14.2 \%$ \\
\hline
\end{tabular}

Table 3 above, indicates that some students rely on social strategies to study vocabulary: asking a friend's help or a teacher to translate word meaning in L1. It is clear these participants are not motivated to use social strategies to build their vocabulary. trategyMemory S 4 Table(statements $10-13$ )

\begin{tabular}{|l|l|r|r|r|}
\hline \multicolumn{2}{|c|}{ Memory strategy } & agree & neutral & disagree \\
\hline & & 8 & 6 & 4 \\
\hline 10 & I group words together to study them. & $46.5 \%$ & $32.3 \%$ & $21.3 \%$ \\
\cline { 3 - 5 } & & 12 & 2 & 4 \\
\hline 11 & I imagine meaning of words. & $65.1 \%$ & $13.2 \%$ & $21.7 \%$ \\
\hline 12 & I say new words aloud when studying. & 13 & 5 & 0 \\
\hline
\end{tabular}




\begin{tabular}{|l|l|r|r|r|}
\hline & & $76.5 \%$ & $23.5 \%$ & $00 \%$ \\
\hline 13 & I usually study the spelling of words. & 12 & 4 & 2 \\
\cline { 3 - 5 } & & $67.4 \%$ & $23.6 \%$ & $09 \%$ \\
\hline
\end{tabular}

Responding to the memory strategy (statements 10 to 13 ), the students are more aware toward using memory strategy. The students possessed positive attitudes toward learning new vocabulary through 'memory strategy'. Significant number of the participants agreed that they "imagine meaning of words", "say new words aloud when studying", and "usually study the spelling of words"; with figures $65.1 \%, 76.5 \%$ and $67.4 \%$ respectively.

Table 5 Cognitive strategy $(14-16)$

Table 5 shows the results of using 'cognitive strategy' by the participants. The results show that the students were highly independent on studying new vocabulary. About $76.4 \%$ take notes in class during lectures. $82.4 \%$ agreed to the statement "I repeat a word many times."

\section{Cognitive strategy .5}

\begin{tabular}{|r|l|r|r|r|}
\hline & Statement & Agree & Neutral & Disagree \\
\hline 14 & .I take notes in class & 12 & 4 & 2 \\
\cline { 3 - 5 } & & $76.4 \%$ & $23.6 \%$ & $09 \%$ \\
\hline 15 & I keep a vocabulary notebook. & 11 & 1 & 6 \\
\cline { 3 - 5 } & & $58.5 \%$ & $7.4 \%$ & $\% .34$ \\
\hline 16 & I repeat a word many times. & 15 & 1 & 2 \\
\cline { 3 - 5 } & & $82.4 \%$ & $8.2 \%$ & $09.4 \%$ \\
\hline
\end{tabular}

Table 6 Meta-cognitive strategy $(17-18)$

\begin{tabular}{|l|l|l|l|l|}
\hline \multicolumn{6}{|l|}{ 6. Meta-cognitive } & Agree & Neutral & Disagree \\
\hline & Statement & 11 & 7 & 0 \\
\cline { 3 - 6 } & I sometimes test myself with word tests. & $61.1 \%$ & $38.9 \%$ & $00 \%$ \\
\hline 18 & I continue to study word regularly. & 7 & 6 & 4 \\
\hline
\end{tabular}




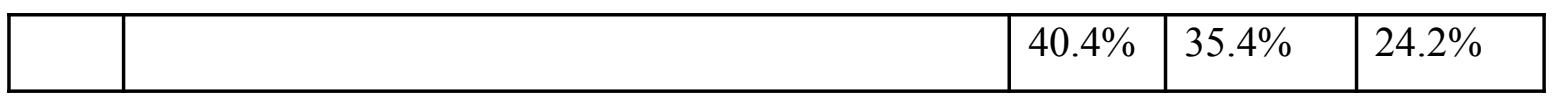

Statements 17 to 18 investigated the students' perception toward using metacognitive strategy. $61.1 \%$ agreed that they sometimes test themselves with a word test. On the other hand none of the students disagreed with this statement; i.e.: "I sometimes test myself with word tests".

\section{2. Findings}

This paper aims at investigating the students' attitudes toward vocabulary learning and their strategies of acquiring them.

The results proved that the students had positive attitudes towards English vocabulary learning (Table 1).They are aware of vocabulary knowledge and they consider that vocabulary is important for studying English language. The results also show that the learners used all five (VLS) categories; cognitive, determination, memory, metacognitive, and social strategies frequently, but unequally.

Referring to statements 4 (table 1) "I devote specific time to learn vocabulary" and 18 (table 6) "I continue study words regularly" only few students agreed with these two points $36.4 \%$ and $40.4 \%$ respectively. This is one of the participants' weaknesses since feedback is necessary to know whether someone stands on firm ground or not.

Considering the most and the least frequent strategies students rely upon, it could be said that the most used strategy is 'Cognitive strategy' and the least is 'Social strategy'. These two facts are the most noticeable to mention.

By looking at the results of the two statements in table 3; "I ask teacher for Arabic translation of the meaning" and "I ask friends for meaning", unfortunately students in this group rarely take advantage to utilize this strategy. It worth mentioning here that language is 
a social human activity, where sometimes mentors are needed insupportive sociability guidance.

One unanticipated finding is that though students were aware of vocabulary importance $-92.8 \%$ who agreed with 'Vocabulary knowledge is important to study English language' - only $36.4 \%$ of the participants allocate specific time to study vocabulary.

The results, generally, show no equality in using the mentioned vocabulary language strategies (VLSs). This limited utility of language learning strategies has negatively affected students' vocabulary knowledge. It is required that the lecturers should regularly encourage and monitor development of this group of students by checking their use of different vocabulary learning strategies to grasp English vocabulary.

\section{3. Conclusions}

In this investigation the aim was to assess two things: firstly, students' attitudes towards vocabulary knowledge and secondly, examining students' vocabulary learning strategies. To measure the attitudes of the participants and VLSs the students used, a questionnaire comprised 18 statements was designed. Data were collected. Results indicated that students were aware of importance of vocabulary in learning a language and they followed different strategies to attain them.

Though the students' vocabulary level is below the expected standard, these findings contribute to understanding how to assist students' vocabulary learning. Fortunately, the results indicate that the students generally have positive attitudes towards vocabulary learning since more than $90 \%$ of the participants claimed that learning vocabulary is significant to study English (Table 1 statement No. 3). The results also show that the students use different VLSs. The most preferable strategy is the 'Cognitive Strategy'. 


\section{4. Implications and Recommendations}

This study was conducted to find out reasons of lack of vocabulary knowledge. Responses from the participants to the questionnaire provided that learners' awareness towards vocabulary learning was positive. The most compelling evidence is that, students had great positive attitudes towards 'vocabulary importance', but they had little tendency to use all strategies equally to study new vocabulary. Based on the findings, the following steps are recommended:

- To boost students' low-attaining vocabulary knowledge, lecturers should direct students to integrate all different strategies to acquire new English vocabulary.

- To build social interaction, lecturers could encourage students to learn more vocabulary through social strategy.

- Future studies are needed to investigate similarity and differences between males and females attitudes towards learning and use of vocabulary learning strategies (VLS) in acquiring new vocabulary. 


\section{References}

Abbas, E., 2016, Vocabulary Learning Strategies Used by Sudanese EFL Learners at University Level, Research Journal of English Language and Literature (RJELAL), Vol.4.Issue 4. 2016 (Oct. Dec)

Adam, S. et al, 2017, Investigating the Effect of Vocabulary Learning Strategies on Vocabulary Achievement amongEnglish Majors at Sudan Universities, SUST Journal of Humanities, (2017) Vol ..18No. 2, ISSN (text): 1858-6724 e-ISSN (online): $1858-67$

Alfaki, I., 2015, Vocabulary Input in English Language Teaching: Assessing the Vocabulary Load in SPINE Five, International Journal of English Language and Linguistics Research Vol. 3, No. 1, pp. 1-14, January 2015

Ali, W., 2016, A Surveyonthe Useof Vocabulary Learning Strategyby ELT and ELL StudentsofDuhok Universityin Kurdistan,International Academic Research Conference in Milan 413,ICBTS Copyright by Author(s) The 2016

Holi, I., 2020,Omani Students Coping Strategies in an English Medium Engineering Programme, Arab World English Journal (AWEJ), Volume 11. Number2 June 2020 Pp. 361-382, DOI: https://dx.doi.org/10.24093/awej/vol11no2.2

Gross, J., 2019, Why vocabulary deficits need your attention: the word gap report, https://bedrocklearning.org/blog/why-vocabulary-deficits-need-your-attention-the-wor d-gap-report/

Larsson, L., 2014,Vocabulary learning: A study of students' and teachers' attitudes towards English vocabulary learning in lower secondary school, Karlstads University 
Mohammed,A., and Ali, M., 2015, The Impact of Sudanese EFL learners' Vocabulary Breadth on their Reading Comprehension, SUST Journal of Humanities (2015) Vol.

16. No.4

Salaheldeen, F. et al, 2015, The Use of Vocabulary Learning Strategies among Sudanese EFL Learners,Journal of Applied Linguistics and Language Research, Volume 2, Issue 6, 2015, pp. 93-102

Waldvogel, D., 2013, The Relationships between Vocabulary Learning Strategies and Vocabulary Size among Adult Spanish Foreign Language Learners, Journal of Language Teaching and Research, Vol. 4, No. 2, pp. 209-219, March 2013

Yeh,C., 2004, An Investigation into Vocabulary Learning Strategies Used by Senior High School Students in Taiwan, Taiwan Journal of TESOL, Vol. 1.2, 1-44, 2004 